\title{
Advanced Instrumentation, Information, and Control Systems Technologies Pathway: FY 2016 External Review
}

Bruce Hallbert Ken Thomas

November 2016

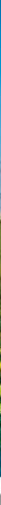

U.S. Department of Energy

Office of Nuclear Energy 


\section{DISCLAIMER}

This information was prepared as an account of work sponsored by an agency of the U.S. Government. Neither the U.S. Government nor any agency thereof, nor any of their employees, makes any warranty, expressed or implied, or assumes any legal liability or responsibility for the accuracy, completeness, or usefulness, of any information, apparatus, product, or process disclosed, or represents that its use would not infringe privately owned rights. References herein to any specific commercial product, process, or service by trade name, trade mark, manufacturer, or otherwise, does not necessarily constitute or imply its endorsement, recommendation, or favoring by the U.S. Government or any agency thereof. The views and opinions of authors expressed herein do not necessarily state or reflect those of the U.S. Government or any agency thereof. 
INL/EXT-16-40568

\title{
Advanced Instrumentation, Information, and Control Systems Technologies Pathway: FY 2016 External Review
}

\author{
Bruce Hallbert \\ Ken Thomas
}

November 2016

Idaho National Laboratory Idaho Falls, Idaho 83415

http://www.inl.gov

Prepared for the

U.S. Department of Energy

Office of Nuclear Engineering

Under DOE Idaho Operations Office

Contract DE-AC07-05ID14517 


\section{SUMMARY}

This report describes an External Review conducted by the LWRS Program Advanced Instrumentation, Information, and Control (II\&C) Systems Technologies Pathway to solicit feedback on the topics and results of the ongoing II\&C research program. This review was held in conjunction with the Nuclear Energy Institute (NEI) Digital I\&C Working Group meeting that was held at Idaho National Laboratory (INL) on August 9-10, 2016. Given the opportunity to visit INL and see the pathway research projects, NEI agreed that the Working Group would serve as the External Review panel for the purpose of obtaining expert input on the value and timing of the research projects. This consisted of demonstrations in the Human Systems Simulation Laboratory followed by presentations on the II\&C research program in general as well as the five technology development areas.

Following the meeting, the presentations were sent to each of the attendees so they could review them in more detail and refer to them in completing the feedback form. Follow-up activities were conducted with the attendees following the meeting to obtain the completed feedback forms. A total of 13 forms were returned. The feedback forms were reviewed by the pathway to compile the data and comments received, which are documented in the report.

In all, the feedback provided by the External Review participants is taken to be a strong endorsement of the types of projects being conducted by the pathway, the value they hold for the nuclear plants, and the general timing of need. The feedback aligns well with the priorities, levels of efforts allocated for the research projects, and project schedules. The feedback also represents realistic observations on the practicality of some aspects of implementing these technologies. In some cases, the participants provided thoughtful challenges to certain assumptions in the formulation of the technologies or in deployment plans. These deserve further review and revision of plans if warranted.

The pathway will take all of the feedback and address the open issues that have been identified by the participants. This includes 11 actionable items for follow up by the II\&C Pathway. 


\section{CONTENTS}

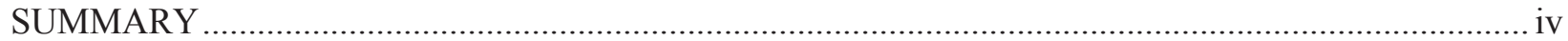

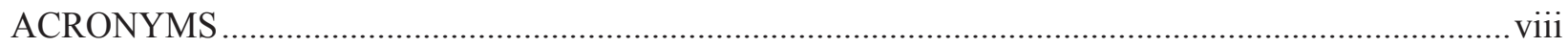

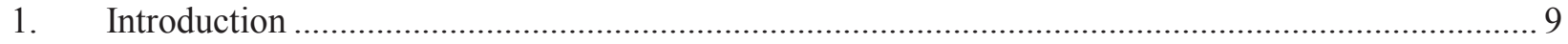

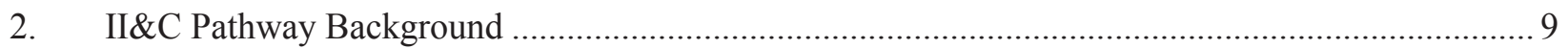

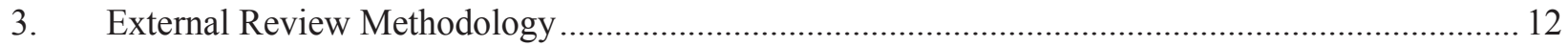

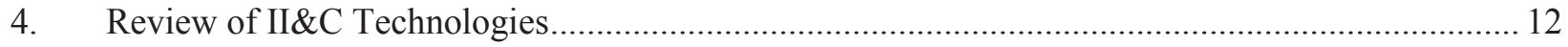

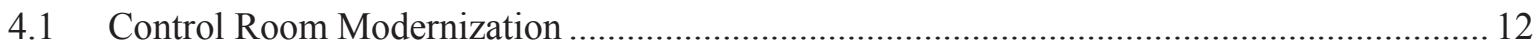

4.1.1 Summary of External Review Feedback and Ratings .......................................... 13

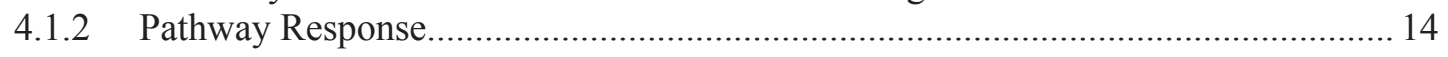

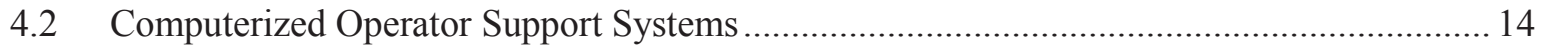

4.2.1 Summary of External Review Feedback and Ratings ............................................ 15

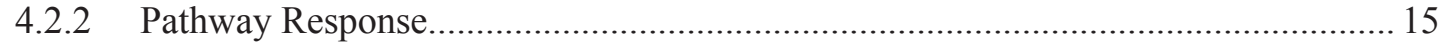

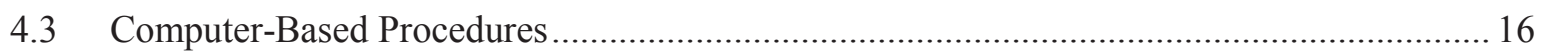

4.3.1 Summary of External Review Feedback and Ratings .......................................... 16

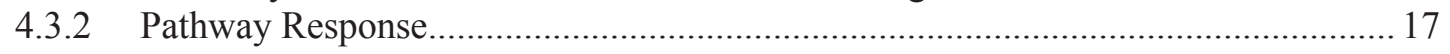

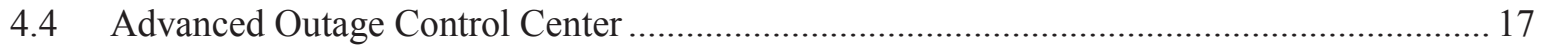

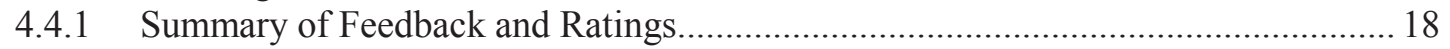

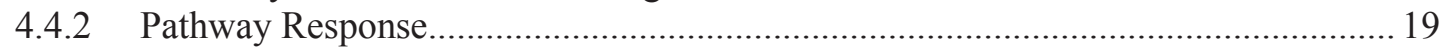

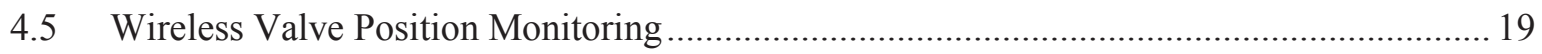

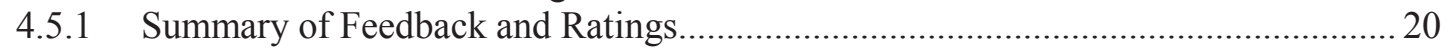

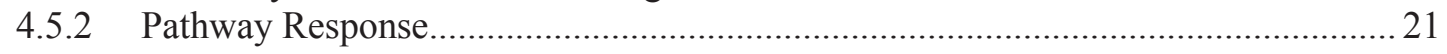

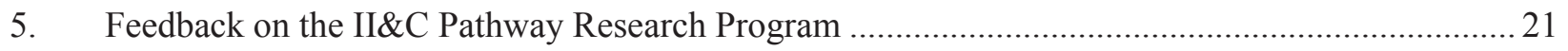

6. Feedback on Additional Research Topics of Interest ............................................................. 22

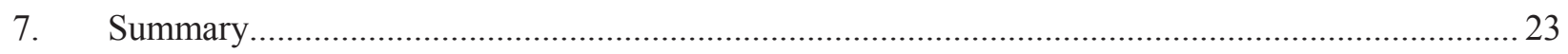

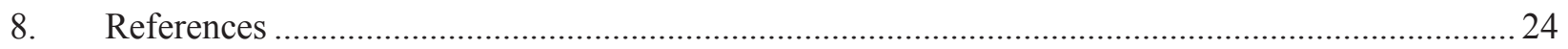

1. Hallbert, B., Thomas, K., Advanced Instrumentation, Information, and Control Systems Technologies Technical Program Plan for FY 2017, INL/EXT 1328055 Revision 6, Idaho National Laboratory, Idaho Falls, ID, 2016 .......................................................................... 24

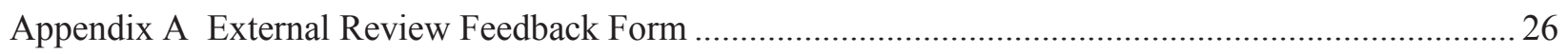

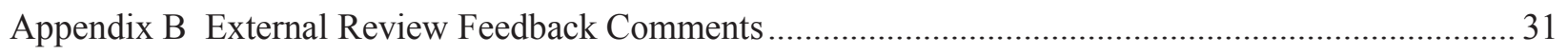

Appendix C External Review Value and Time Frame Ratings ......................................................... 35 


\section{FIGURES}

Figure 1. II\&C Pathway Areas of Enabling Capabilities............................ Error! Bookmark not defined. 


\section{ACRONYMS}

$\begin{array}{ll}\text { ALWR } & \text { advanced light water reactor } \\ \text { COSS } & \text { computerized operator support system } \\ \text { DOE } & \text { Department of Energy } \\ \text { EPRI } & \text { Electric Power Research Institute } \\ \text { HMI } & \text { Human-Machine Interface } \\ \text { HSSL } & \text { Human Systems Simulation Laboratory } \\ \text { II\&C } & \text { Instrumentation, Information, and Control } \\ \text { INL } & \text { Idaho National Laboratory } \\ \text { INPO } & \text { Institute of Nuclear Power Operations } \\ \text { I\&C } & \text { Instrumentation and Control } \\ \text { LWRS } & \text { Light Water Reactor Sustainability } \\ \text { NEI } & \text { Nuclear Energy Institute } \\ \text { NEWPER } & \text { Nuclear Electronic Work Packages - Enterprise Requirements } \\ \text { NITSL } & \text { Nuclear Information Technology Strategic Leadership } \\ \text { NPP } & \text { nuclear power plant } \\ \text { O\&M } & \text { operating and maintenance }\end{array}$




\section{Advanced Instrumentation, Information, and Control Systems Technologies Pathway: FY 2016 External Review}

\section{Introduction}

This report describes an External Review conducted by the LWRS Program Advanced Instrumentation, Information, and Control (II\&C) Systems Technologies Pathway to solicit feedback on the topics and results of the ongoing research program. This review was held in conjunction with the Nuclear Energy Institute (NEI) Digital I\&C Working Group meeting that was held at Idaho National Laboratory (INL) on August 10-11, 2016. Due to ongoing collaboration between the pathway and NEI on regulatory issues affecting digital implementation in nuclear power plants, NEI held its quarterly meeting at INL for the purpose of seeing firsthand the technologies that are being developed and to understand more how they can improve performance for the nuclear fleet. In addition, NEI desired to know more about the technologies from the standpoint of potential regulatory issues that must be addressed to enable industry implementation.

The NEI Digital I\&C Working Group is made up of industry leaders in I\&C and related regulatory issues from the nuclear utilities, nuclear suppliers, and industry support groups. The industry support groups, in addition to NEI, includes the Electric Power Research Institute (EPRI) and the Institute of Nuclear Power Operations (INPO). This working group was chartered by the chief nuclear officers of the nuclear utilities to work with the Nuclear Regulatory Commission to resolve the regulatory issues that are impeding the implementation of digital technologies.

Given the opportunity to visit INL and see the pathway research projects, NEI agreed that the Working Group would serve as the External Review panel for the purpose of obtaining expert input on the value and timing of the research projects.

This report provides the background on the work of the II\&C Pathway, and then presents the feedback of the External Review participants for each of five technology areas representative of the research being conducted at this time. In addition, general feedback on the II\&C research program is provided, along with additional topics for research suggested by the participants.

\section{II\&C Pathway Background}

The Advanced Instrumentation, Information, and Control (II\&C) Systems Technologies Pathway, part of the Department of Energy Light Water Reactor Sustainability (LWRS) Program, conducts targeted research and development (R\&D) to address aging and reliability concerns with the legacy instrumentation and control and related information systems of the U.S. operating light water reactor (LWR) fleet. [1] This work involves two major goals: (1) to ensure that legacy analog II\&C systems are not life limiting issues for the LWR fleet, and (2) to implement digital II\&C technology in a manner that enables broad innovation and business improvement in the nuclear power plant (NPP) operating model. [1] Resolving long term operational concerns with the II\&C systems contributes to the long term sustainability of the LWR fleet, which is vital to the nation's energy and environmental security.

Reliable instrumentation, II\&C systems technologies are essential to ensuring safe and efficient operation of the U.S. LWR fleet. These technologies affect every aspect of NPP and balance of plant operations. They are varied and dispersed, encompassing systems from the main control room to primary 
systems and throughout the balance of the plant. They interact with every active component in the plant and serve as a kind of central nervous system.

Current instrumentation and human machine interfaces in the nuclear power sector employ analog technologies. In other power generation sectors, analog technologies have largely been replaced with digital technologies. This is in part due to the manufacturing and product support base transitioning to these newer technologies. It also accompanies the transition of education curricula for II\&C engineers to digital technologies. Consequently, product manufacturers refer to analog II\&C as having reached the end of its useful service life. Although considered obsolete by other industries, analog II\&C continues to function reliably, though spare and replacement parts are becoming increasingly scarce as is the workforce that is familiar with and able to maintain it. In 1997, the National Research Council conducted a study concerning the challenges involved in modernizing existing analog based instrumentation and controls with digital instrumentation and control systems in NPPs. [2] Their findings identified the need for new II\&C technology integration; 20 years later this has not yet been achieved.

Replacing existing analog with digital technologies has not been undertaken to a large extent within the U.S. nuclear power industry. Those efforts that have been carried out are broadly perceived as involving significant technical and regulatory uncertainty. This translates into delays and substantially higher costs for these types of refurbishments. Such experiences have slowed the pace of analog II\&C replacement and further contribute to a lack of experience with such initiatives. In the longer run, this may delay progress on the numerous II\&C refurbishment activities needed to establish plants that are cost competitive in future energy markets when plants enter long-term operation. Such delays could lead to an additional dilemma: delays in reinvestment needed to replace existing II\&C systems could create a "bow wave" of needed future reinvestments. Because the return period on such reinvestments becomes shorter the longer they are delayed, they become less viable. This adds to the risk that II\&C may become a limiting or contributing factor that weighs against the decision to operate nuclear power assets for longer periods.

II\&C replacement represents potential high cost or high risk activities if they are undertaken without the needed technical bases and experience to facilitate their design and implementation. The II\&C R\&D program addresses critical gaps in technology development and deployment to reduce risk and cost. The objective of these efforts is to develop, demonstrate, and support deployment of new digital II\&C technologies for nuclear process control, enhance worker performance, and provide enhanced monitoring capabilities to ensure the continued safe, reliable, and economic operation of the nation's NPPs.

Within this R\&D framework, six areas have been identified that enable capabilities needed for long term sustainable plant operation. Through a consensus development process involving industry staff representing $70 \%$ of the existing LWR fleet, these areas were identified to address the aging of existing II\&C technologies, to create capabilities needed to enable power plant staff to perform their jobs more efficiently with digital technologies, and to create the underlying digital II\&C architecture that is needed by plants during periods of long-term operation. These are shown in Figure 1. In each of these areas, a series of pilot projects are planned that enable the development and deployment of new II\&C technologies in existing nuclear plants. Through the Light Water Reactor Sustainability (LWRS) program, individual utilities and plants are able to participate in these projects or otherwise leverage the results of projects conducted at demonstration plants. 


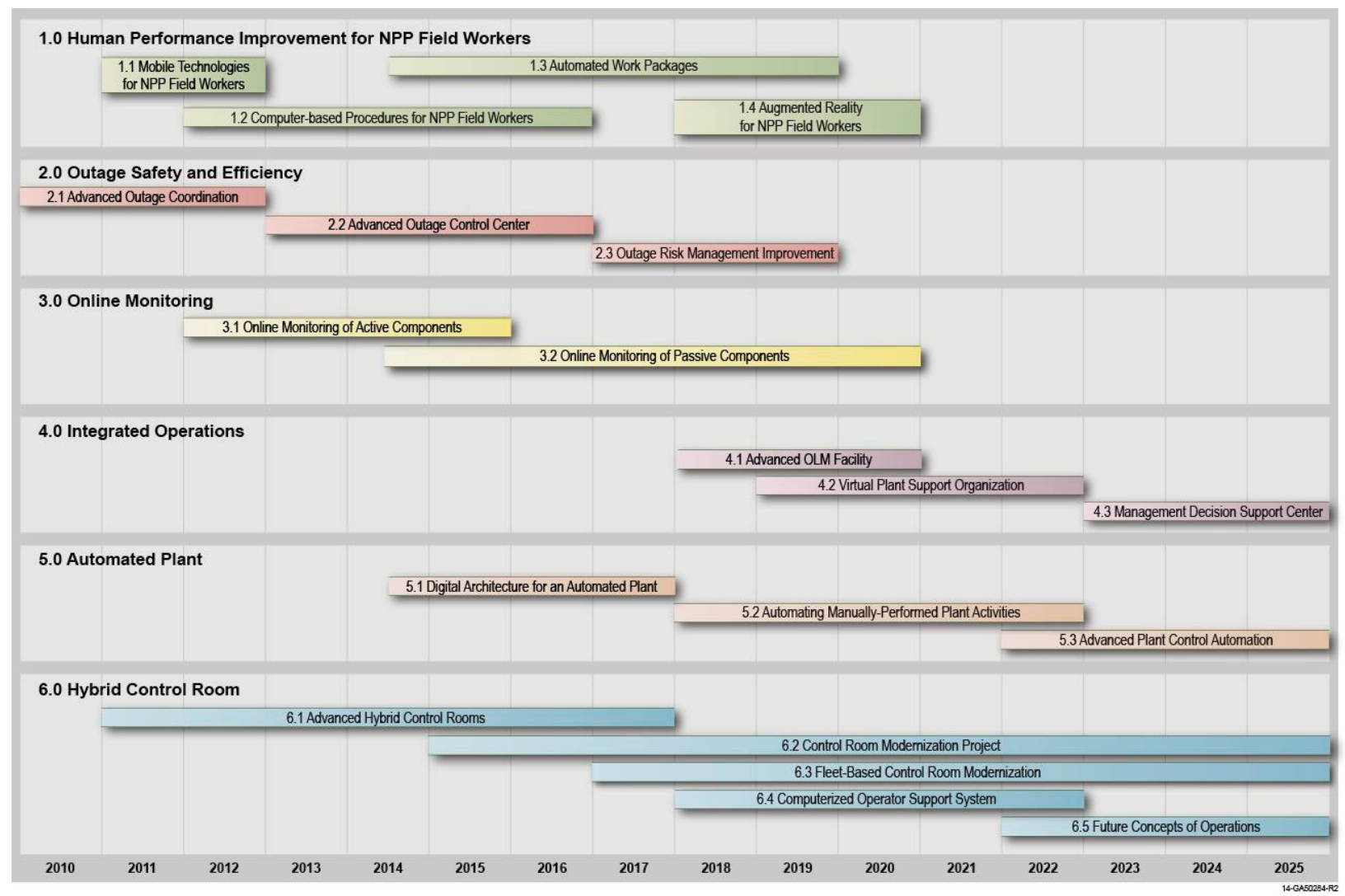

Figure 1. II\&C Pathway Area of Enabling Capabilities

The pilot projects conducted through this program serve as stepping stones to achieve longer term outcomes of sustainable II\&C technologies. They are designed to emphasize success in some crucial aspect of plant technology refurbishment and sustainable modernization. They provide the opportunity to develop and demonstrate methods to technology development and deployment that can be broadly standardized and leveraged by the commercial nuclear power fleet. Each of the R\&D activities in this program achieves a part of the longer term goals for safe and cost effective sustainability. They are limited in scope so they can be undertaken and implemented in a manner that minimizes technical and regulatory risk. In keeping with best industry practices, prudent change management dictates that new technologies are introduced slowly so that they can be validated within the nuclear safety culture model.

A key tenet of the Advanced II\&C Systems Technologies Pathway is to continuously engage the nuclear power industry to ensure a correct understanding of the II\&C issues and requirements as currently experienced in the operating nuclear power plants, and to develop approaches to address aging instrumentation and control systems and demonstrate these systems in individual pilot projects with operating NPPs. This provides validation of the developed technologies as fully meeting utility requirements. The results can be used by other owner operators to address similar aging issues and to achieve new efficiencies. This approach is unique to this pathway and is essential because future planned R\&D efforts are built on the concepts and successes from prior projects. This creates a stepwise approach to long term modernization and refurbishment of instrumentation and control technologies across the LWR fleet. The engagement strategy with nuclear utilities serves to identify priorities for modernization and safety enhancement, timeframes for action, a means of coordinating resources and research partnerships, and a forum to communicate the results of research efforts to the broader nuclear industry and vendor community. 


\section{External Review Methodology}

The External Review was conducted with the panel of attendees at the August NEI Digital I\&C Working Group meeting held at INL on August 10-11, 2016. This consisted of demonstrations in the Human Systems Simulation Laboratory followed by presentations on the II\&C research program in general as well as the five technology development areas. A feedback form was given to the participants and is provided in Attachment A.

Following the meeting, the presentations were sent to each of the attendees so they could review them in more detail and refer to them in completing the feedback form. Follow-up activities were conducted with the attendees following the meeting to obtain the completed feedback forms. A total of 13 forms were returned.

The feedback forms were reviewed by the pathway to compile the data and comments received, which are documented in the report.

\section{Review of II\&C Technologies}

The following sections present the data and comments for the five technology areas as provided in the feedback forms received from the participants in the External Review. For each area, a description is first provided of the technology and motivation for development. This is followed by the a summary of the External Review feedback for both the value and time frame ratings. Then the II\&C Pathway response to the feedback is provided, addressing the comments, concerns, and suggestions.

The complete set of comments from the participants is found in Appendix B. The value and timeframe ratings, and associate averages, are found in Appendix C.

\subsection{Control Room Modernization}

Nuclear utilities are facing significant problems with obsolescence and reliability of their legacy instrumentation and control systems, most of which are based on declining analog technologies. As they initiate upgrade projects to address these issues, there is an opportunity to modernize the control rooms in ways that improve plant operations and reduce operator errors.

The II\&C Pathway has partnered with five major nuclear utilities in the area of control room modernization. Making use of a world-unique facility known as the Human Systems Simulation Laboratory (The II\&C Pathway has partnered with five major nuclear utilities in the area of control room modernization. Making use of a world-unique facility known as the Human Systems Simulation Laboratory (HSSL), the Pathway is able to conduct high-fidelity simulations of control rooms for operating nuclear plants that includes mixtures of a variety of digital instrumentation and control technologies, allowing licensed operators from the partner utilities to experience the use new control room technologies in the context of their own plant simulator and custom-designed scenarios. This allows the project team to directly measure the benefit of proposed digital technologies through operator in the loop studies and compare them with current technologies and capabilities. It also provides a means to ensure that human factors considerations for planned operator use are optimized at the outset of a modernization project, thereby ensuring that the modernized control room will deliver performance improvements.

During the week that the External Review participants visited, a crew of licensed control room operators were at the INL to support a control room modernization workshop. The operating crew was provided to support the workshop by the participating utility, who was also represented in the External 
Review group. The External Review participants were provided with a live demonstration of these advanced control room technologies and related research methods, including hands-on control of the simulator. This included a planned system upgrade for turbine control as well as an overview of a longer term planned control room modernization effort with a sponsoring utility. Control room operators also demonstrated their use of the HSSL for purposes of conducting a control room design workshop, and demonstrated how they use and interact with the simulator during a pre-programmed scenario for demonstration purposes. INL researchers provided a discussion while in the HSSL about some of the different methods that are or may be used to objectively measuring the effects of new technologies in a control room setting, and several were demonstrated to the external review participants.

\subsubsection{Summary of External Review Feedback and Ratings}

Value Rating $=4.5$

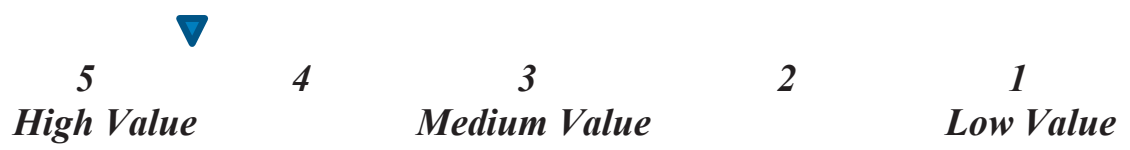

Of the five technologies areas that were demonstrated to the External Review participants, control room modernization was rated the highest value to the industry, with an average rating of 4.5 on the fivepoint scale. Participants noted that control room modernization was necessary to ensure continued reliable operation of the nuclear fleet, as well as to enable life extension. Control room modernization was also cited as a potential means of staffing reductions to remain cost competitive. It was stated that every other industry has modernized its controls, particularly aviation, and that the nuclear industry should not be lagging in the area. The Pathway work was recognized for getting ahead of the moving the industry forward with strategic planning and best practices in integrating digital human-machine interface (HMI) technology. It was also commended for involving the operators upfront in the modernization efforts.

Concerns expressed included the cost to modernize control rooms and the regulatory barriers to implementing digital technology.

Time Frame Rating $=3.7$

$\begin{array}{ccccc}5 & 4 & 2 & 1 \\ \text { Now } & \text { Next } 5 \text { Years } & & \text { Next } 10 \text { Years }\end{array}$

The feedback on time frame from the External Review participants is that this technology is needed in less than five years. Comments indicate that the need is urgent and that the problems will only grow worse with delay. However, the timing is a function of the cost, and that the degree of modernization for any given plant will be a function of its remaining life. That is, the external review participants voiced that control room modernization represent investments and, like all investments, are viewed within the context of a likely return period. Participants recognized that control room modernization is a long process that will have to be accomplished over multiple refueling cycles. One response indicated that the timing will accelerate once the industry recognizes the benefits. 


\subsubsection{Pathway Response}

The pathway is substantially aligned with the opinion of the External Review participants that control room modernization has the highest value to the industry of the technology areas presented, in that it has the highest funding and level of effort within the pathway.

It should be noted that the current projects with utility partners are not demonstration projects, but rather actual design projects in which the Pathway is working with these partners to modernize their control rooms. That said, technologies will be introduced over time as certain research activities are completed. The point is that the Pathway is approaching this work in a manner that addresses the relatively short time frame of the industry need.

Regarding the concerns on regulatory barriers, the pathway is working with the Nuclear Energy Institute (NEI) to support resolution of issues that would impede the upgrade of I\&C systems and control room modernization. The pathway participates in the NEI Digital I\&C Working Group, which works with the Nuclear Regulatory Commission (NRC) to address these issues. In addition, the pathway has initially selected projects with utility partners that are focused on non-safety I\&C systems where there are less regulatory barriers. This will enable the industry to gain valuable, confidence-building experience with control room modernization while the issues with safety-related I\&C systems are resolved.

Concerning the cost of control room modernization, it has been difficult for the industry to quantify the return on investment. For this reason, the pathway conducted a project in FY 2016 to develop a business case for control room modernization. This was published as a pathway report, INL/EXT-1639098, A Business Case for Nuclear Plant Control Room Modernization [3], which documented an annual return on investment of $\$ 1.7 \mathrm{M}$ per year for a typical two unit NPP. Further work will be done in FY 2017 to investigate the business case in more depth and for a range of implementation options.

In summary for control room modernization, the present direction aligns with the External Review feedback and no substantial changes to project plans are needed.

\subsection{Computerized Operator Support Systems}

A computerized operator support system (COSS) is a collection of capabilities to assist operators in monitoring overall plant performance and making timely, informed decisions on appropriate control actions for the projected plant condition [4]. They generally have the following features:

- Monitoring a process to detect off-normal conditions

- Diagnosis of plant faults

- Prediction of future plant states

- Recommendation of mitigation alternatives

- Decision support in selecting mitigation actions.

COSS is not an extension of the control systems, but rather serves as an advisory system for operators to use as it is helpful. It does not impose on their licensed responsibilities to monitor and control the plant. The technology is based on a reasoning process which is transparent and familiar to the operator as it is very nearly the same qualitative reasoning process through which the operator would make a fault diagnosis, given sufficient time and access to instrument readings [5].

The COSS technology was presented to the External Review participants as a potential future development project for the pathway. The demonstration provided was of a prototype technology that was developed under another Department of Energy program. However, since this prototype made use of the same simulation models in the HSSL, it was included in the demonstration of control room 
modernization technology. The purpose in presenting it was to gauge industry interest in this as a control room technology, and to hear gain specific feedback on both the value and concerns with developing such a technology.

\subsubsection{Summary of External Review Feedback and Ratings}

Value Rating $=3.7$

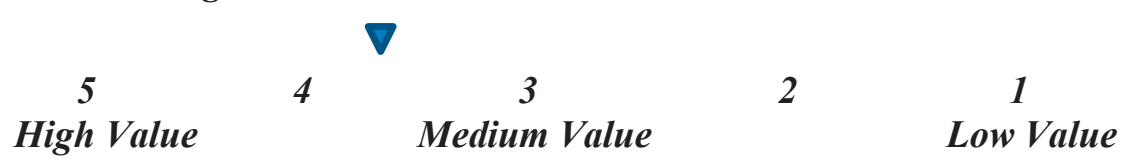

There were fewer comments on the value of computerized operator support systems, probably due to the fact that this technology has no counterpart in today's analog control rooms and therefore its role in the control room is not as straightforward. One participant expressed some uncertainty about the value of the technology, saying that it was interesting technology, but it is not clear that it solves a significant problem for utilities. That said, overall this technology received an average value rating of 3.7, which puts it on the higher end of the scale. It was noted that this technology would facilitate operator staff reduction because it reduces operator task burden in routine evolutions and abnormal events. It was seen by two participants as a means of improving overall plant reliability due to its ability to reduce error rates.

Time Frame Rating $=3.3$

$\begin{array}{ccccc}5 & \nabla & & \\ \text { Now } & 4 & \text { Next } 5 \text { Years } & & \text { Next } 10 \text { Years }\end{array}$

External Review participant feedback on the time frame was that it is not as high of priority as other technologies presented. However, it still received an average score of 3.3, which places it within the next five years. One participant noted that it would be especially needed as plant transition to a load following or frequency regulating operating mode.

\subsubsection{Pathway Response}

The feedback does confirm that the technology has value to utilities in reducing plant events due to operator error. The pathway agrees that COSS technology is a longer term technology than most of the other areas, as it is less mature and does not have a clear commercialization path at this time. However, at least one nuclear operating utility has expressed interest in deploying it in the near term.

It is clear that more work is needed to articulate the benefits to industry and relate them to the issues they are dealing with now. Specific focus should be in the potential role of this technology in improving plant monitoring, which has been cited by the Institute of Nuclear Power Operations (INPO) as a performance gap for nuclear operations [6].

In summary, the pathway will proceed with development of COSS technology, and will seek opportunities to engage nuclear utilities and suppliers on the potential benefit of this technology, as well as practical constraints within the concept of operations for the operating fleet control rooms. 


\subsection{Computer-Based Procedures}

Computer-based procedures are electronic counterparts of traditional paper-based procedures that provide a rich set of features to increase work efficiency and preclude human errors. These features include automatic place keeping, automatic branching based on work scope, component identification technology, computational aids, automatic notifications, data verification such as range checking, access to supplementary electronic documents, access to training aids, and many more features.

Computer-based procedures can be deployed both for control room operators and field technicians. They can be shared among workers so that work is properly coordinated. They can be accessed remotely for real-time sign-offs such as control room authorization. And they can be electronically routed for approvals and archival at the completion of the job.

The pathway has developed a working prototype of a computer-based procedure system that demonstrates these types of features. These features were demonstrated for the External Review participants in both in simulated control room and field work settings.

\subsubsection{Summary of External Review Feedback and Ratings}

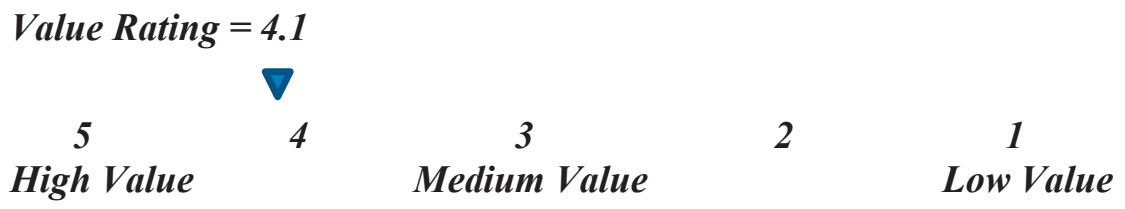

The majority of the feedback from the External Review participants endorsed the value of computerbased procedures in reducing operating costs. The pathway efforts were described as an "excellent initiative" in saving costs for utilities in light of the current economic situation for the industry. Two of participants made note of the ability to provide real-time work status, thereby improving work coordination.

A couple of the participants recognized the benefits in reducing paper usage as well as reducing rad waste by not taking paper into contaminated areas. In addition, they noted that is solves the problem of the "lost or misplaced work order" which is a significant problem when it is the only verified documentation that work was completed according to requirements.

One supplier among the participants described it as an interesting technology, but was not sure if this was solving a significant problem. This comment was in stark contrast to the rest of the comments and it is not known whether it reflects a lack of familiarity with the issues nuclear plants are facing in paperbased work processes. In any case, it at least indicates that there is still work to do in informing the industry of the benefits of digital technologies and clearly relating them to the operational challenges being experienced by the operating plants.

Finally, one participant noted that computer-based procedures represent the future for the "next generation" nuclear worker, alluding to the fact that the new workforce is immersed in an electronic world and relies on personal devices to conduct virtually all personal business.

In all, the value rating average was 4.1 , making it the second highest rated of the five technology areas, behind only control room modernization. 
Time Frame Rating $=3.8$

$\begin{array}{ccccc} & \nabla & & \\ 5 & 4 & 3 & 2 & 1 \\ \text { Now } & & \text { Next } 5 \text { Years } & & \text { Next } 10 \text { Years }\end{array}$

The feedback on time frame for implementation was that it is urgent for the cost savings benefits that are needed in the current economic climate, but that it is also difficult and labor intensive to implement. Recommendations were to look for the subset with the greatest value. One participant thought that it will be difficult to justify for small, non-fleet plants.

On the other hand, some saw it as an opportunity, stating that the sooner it is implemented, the more benefits will be obtained. Similarly, one participant noted that human performance errors are the most significant threat to plant availability and safety, underscoring the urgency to implement this technology.

\subsubsection{Pathway Response}

The pathway is in agreement with the idea that computer-based procedures are one of the largest enablers of cost reduction for the operating plants, and has prioritized this work accordingly for over four years. This technology is maturing rapidly and is in the beginning phases of commercialization, a least for the first phase of features. The pathway will continue to develop more advanced features, particularly as computer-based procedures are included as an important component of automated work packages, thus broadening the application of the efficiency and human performance features.

It is recognized that the cost and effort to implement this technology is challenging. Research has been directed towards the task of converting the existing base of paper procedures and the pathway will continue to work with industry groups and suppliers to develop technology to address this need as well.

It should be noted that the pathway has been very active with the industry in helping first-movers adopt this technology. This has been through the Procedure Professionals Association and the INPOsponsored Nuclear Information Technology Strategic Leadership (NITSL) and more specifically the NITSL Infrastructure and Application Committee. Partnering with NITSL has led to the development of the Nuclear Electronic Work Packages - Enterprise Requirements (NEWPER) which is being developed as an industry common specification for computer-based procedures and automated work packages.

As mentioned above, there is continuing need to inform the nuclear industry stakeholders of the importance of this technology, and the pathway will continue to support this with publications and participation in related conferences, as well as direct interaction with the utility, supplier, and industry support community.

\subsection{Advanced Outage Control Center}

Reducing refueling outage durations is perhaps the largest remaining opportunity to increase the capacity factors of the operating nuclear plants, which would have a direct and significant positive impact on the economic viability of the nuclear fleet. Outage execution improvement would also enhance nuclear safety by avoiding events where plant defense-in-depth is compromised through lack of coordination of critical work activities.

The pathway has conducted research in outage improvement since 2010, developing a number of prototype technologies that enhance outage communication and coordination, address emergent outage 
issues, and provide an analytical basis for rapid decision making. One of these technologies, emergent issue resolution, was recognized in an NEI TIP Award as a result of the success of a utility partner. More recent efforts have focused on optimizing outage control centers from a human performance perspective, creating an immersive information environment that facilitates both electronic and face-to-face interactions, enabling real-time collaboration with geographically-dispersed team members.

These technologies were presented to the External Review participants, along with examples of implementation from the many utility partners that are participating in the work of the pathway to improve outage performance. It should be noted that the majority of the work with utility collaborators have applied the technologies in actual outage work rather than stand-alone demonstration efforts, thus confirming the confidence that utilities have placed in these developments.

\subsubsection{Summary of Feedback and Ratings}

Value Rating $=4.0$

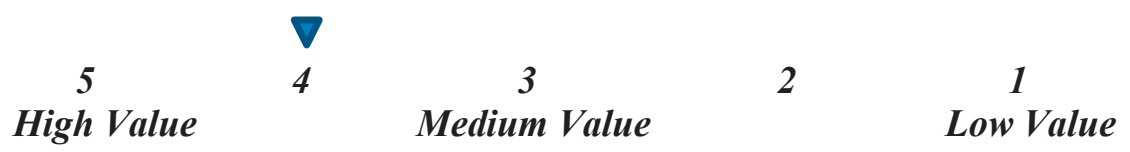

Feedback from the External Review participants places a high value on the work of the pathway to improve outage execution, with one respondent basing this opinion on the results achieved so far. The linkage to improved capacity factors was noted in the comments. The complexity of outages was acknowledged with the need for improved information flow to support decision making. Correctly executing outage activities was also seen as a positive outcome of these technologies.

One participant suggested the need for a business case documenting what plants have experienced that have implemented these technologies, as a means of helping plants move forward with decisions to implement these types of technologies. Another participant noted that many outage control centers had been upgraded in the past ten years and it wasn't clear how much more benefit there is to be gained.

In all, the relatively high ranking (4.0) of the value of these technologies suggests that the majority of the respondents believe the utilities have much to gain in deployment of the various outage technologies being developed by the pathway.

Time Frame Rating $=3.8$

\begin{tabular}{ccccc} 
& \multicolumn{1}{r}{} & & \\
5 & 4 & 3 & 2 & 1 \\
Now & & Next 5 Years & & Next 10 Years
\end{tabular}

Regarding the time frame for implementing the outage technologies, the comments from the External Review participants reflect an understanding that this will vary for each utility based on their current practices and success. It was noted that these technologies can be implemented without regulatory approval, and so there would be no delay in that regard. It was also stated that this should be a function of continuous improvement of outage processes, implying that the technologies can be introduced on an ongoing basis as they address the improvement needs of any given utility. 
A time frame average rating of 3.8 indicates that most plants would benefit by the adoption of these technologies in the next couple of years. This is a reasonable timeframe given the effort needed to make large changes, such as a reconfigured outage control center, and adoption of various collaboration and coordination activities involving large displays and integration of discrete information sources. Some developments in analytics and outage risk management will be available on a longer time line.

\subsubsection{Pathway Response}

The pathway agrees with the consistent feedback from the External Review participants that this is an important area of development relative to nuclear plant cost management and performance improvement. This matches input obtained from the utility partners in the technology developments and initial deployments.

Regarding the comment that a business case should be developed. this has been done in one case previously mentioned in the documentation supporting the NEI TIP award for addressing emergent outage issues. In addition, the pathway conducted a business case study on the benefits of advanced outage technologies at a large two-unit nuclear plant. The results were published in a pathway report INL/EXT-16-38265, A Business Case for Advanced Outage Management. [7] This report documented a potential annualized savings of over $\$ 27 \mathrm{M}$. However, there is clearly more opportunity to document the benefits of the utility collaborators in the initial implementation of these technologies as a means of encouraging more utilities to take advantage of the cost and safety benefits that are available in advanced outage management.

The pathway agrees that many plants have upgraded outage control centers over recent years., but observes that the processes and methods used to manage outages are largely the same. For example, they are still based on a series of predefined central meetings with a large number of attendees to report status and to receive tactical direction. Methodologies employed are still mostly computer-generated lists, telephone and radio communications, email, and white board problem solving. There is some growing use of video to monitor remote activities. However, the opportunity to employ advanced collaboration technologies, to make work activity status self-reporting through electronic documents, to rapidly disseminate changing outage information through social media-type applications, etc. - have not yet been exploited even in these upgraded outage control centers. The bottom line is there are available and emerging technologies, some familiar to us in our use of smart device applications, that can rapidly transform the management of such large, fluid undertakings as a nuclear refueling outages.

\subsection{Wireless Valve Position Monitoring}

Plant configuration management in operating plants is highly dependent on large technical staffs conducting manual verifications of components positions, such as valves, breakers, and dampers, because a majority of plant components do not have remote position indication available to the operators [8]. In addition, the importance of these component positions and line-up required a second, and sometimes even a third verifier, increasing the cost performing these surveillances. Moreover, although small on a percentage basis, there is an ongoing problem of position errors for components in spite of all the efforts to manage configuration. Some of these reduce plant availability, impact regulatory compliance, and have significant safety implications.

Most plant component positions have to be verified by a second person and sometimes even a third in high-risk situations. This is a prime example of why nuclear operations have become so expensive compared to other forms of electric generation, when it requires two qualified technicians to do the work of one. How much more beneficial it would be if even the work of the one in configuration management could be eliminated. 
To this end, EPRI contracted INL to develop prototype technology to provide reliable, wireless component position indication directly to configuration management applications that could verify that regulatory and operational line-ups of components were in conformance with requirements. Such technologies were developed and packaged in prototype form, and tested in a suitable flow loop facility operated by Idaho State University. The research proved to be very successful in concept and now awaits suitable commercialization arrangements to provide solid product offerings that can be deployed in operating nuclear plants.

The pathway has incorporated this technology into its larger vision of a seamless digital environment for plant processes and workers to have the information available to conduct safe and efficient nuclear operations at significantly reduced cost. This initial work is viewed as an important step in what will be a massive transformation in how nuclear plant information is acquired and processed. The potential to eliminate expensive labor requirements and reduce human error is enormous.

The External Review participants were provided information and demonstrations (via video) of the technology and how it impacts routine plant operations.

\subsubsection{Summary of Feedback and Ratings}

Value Rating $=3.1$

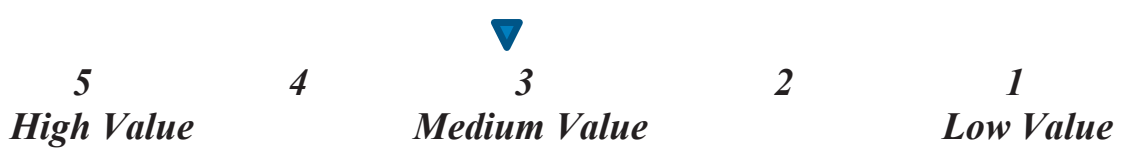

The feedback from the External Review participants indicate that this is a promising development but less of a priority than the other technology areas. The value of the technology was well-stated by the respondents, noting the reduction in effort for valve line-up verifications, having instantaneous monitoring of plant equipment status, and elimination of untimely discoveries in component position errors. It was also viewed as a potential first step into wireless instrumentation for the plants.

Constraining factors were noted in the feedback, such as the need for broad wireless implementation and cyber security concerns. The need for a business case to support the deployment was also mentioned. One other comment made an indirect reference as to whether the technology could scale up to full plant deployment, and if so, it could be quite valuable.

One respondent stated that plants have focused on plant configuration control for some time to reduce the threat of component position errors. However, this technology would be of significant benefit in maintaining plant safety in the future when operations staffing will have to be reduced for economic reasons.

The value rating average of 3.1 is consistent with the External Review comments, in that it has very good potential but there are several practical deployment factors that need additional investigation.

Time Frame Rating = 2.7

5

Now

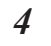

(1)


The time frame average rating (2.7) from the External Review participants indicated that it will be needed in five to ten years, and then if it was coupled with control room modernization and operations staffing reductions. On a priority basis, it is not as urgent as the other technology areas.

\subsubsection{Pathway Response}

The pathway agrees with the feedback of the External Review participants that this is a less mature and longer term technology than the other areas. The pathway recognizes that the industry has achieved considerable improvement in plant configuration control though use of human performance techniques. Where there might be some divergence of views between the pathway and the External Review participants is whether the potential to reduce labor costs is fully appreciated.

However, the constraining factors that were mentioned certainly need to be investigated and resolved if this technology is to be successful. This includes the concerns of wide-scale wireless deployment and cyber security of wireless. The pathway is involved in activities addressing both of these concerns and will ensure that this technology is fully considered.

The idea of a business case for wireless component position indication, with perhaps related uses of wireless implementation, will be considered for possible future efforts. This might serve as the means to explore the potential of this technology to play a meaningful role in nuclear plant cost reduction as part of the current industry focus known as Delivering the Nuclear Promise. Part of this might possible entail limited pilot at an operating nuclear plant to demonstrate its benefits in actual operating conditions.

The pathway acknowledges that the current state of this technology likely puts it into a timeframe of beyond five years, matching the view of the External Review participants. It would take a significant focus to bring it to commercial product status and implement at a plant wide scale in less time.

\section{Feedback on the II\&C Pathway Research Program}

The following are the comments of the External Review participants on the overall value of the II\&C Pathway research program based on the background, presentations, and demonstrations they received during their visit to INL on August 9-10, 2016.

- Great program. Glad to see INL working directly with utilities to solve their problems. (utility representative.

- Very enlightening presentations. (supplier representative)

- Concrete degradation is an excellent initiative for plants seeking life extension. (supplier representative)

- LWRS is a valuable research program that can and has had impact on the nuclear power sector. (industry support organization representative)

- LWRS summary was very valuable. Much of the research I had some awareness of but really didn't know who was leading. (utility representative)

- I am involved in the control room upgrades and human factors aspects of this. The LWRS research in this area is directly applicable to our efforts. The research is methodical and provides great value to us both directly (evaluating our upgrades) and indirectly (imparting the 
basics of human factors engineering to our engineers) for future upgrades. (utility representative)

- The tour and presentations were very well done \& informative. Continue or expand collaboration with NEI to enhance ability to solicit optimum industry involvement and inclusion in all relevant INL programs. (industry support organization representative)

- This program continues to provide benefit and will become increasingly important as plants age and the demographic shifts to younger workers. (industry support organization representative)

- Great effort focused on helping the industry to become more effective in controlling and monitoring plant activities. (utility representative)

- Great to see all the initiatives underway.(industry support organization representative)

- In general, the mission of the LWRS Program is very beneficial for the industry. However, with limited funding available for this research, and with utilities constantly being pressured to reduce costs, the focus of the research should be on high impact improvements that will have immediate payback for utilities. (supplier representative)

- Highly beneficial to the nuclear industry to ensure nuclear remains competitive with other energy sources. (supplier representative)

- Program is very valuable and beneficial to the nuclear industry. However, the program needs to be better known by others to generate more ideas and support. (supplier representative)

The feedback from the External Review participants on the general value of the II\&C Pathway research program is considered to be very positive. A couple of the responses indicate the need for additional industry communication concerning the technology developments of the pathway.

\section{Feedback on Additional Research Topics of Interest}

The feedback from given to the External Review participants asked whether there were additional research topics that should be considered by the II\&C Pathway. The following is the listing of those topics provided.

1. Automation of data collection and analytics. Goal: eliminate to the maximum expert activities presently performed by humans.

2. Application of drones and robotics in power plants. Many tasks performed by humans: routine inspections, physical security, operator rounds, engineering walkdowns, can be performed by drones/robots. Humans' five senses can be emulated today by sensing technologies, in fact sensing technologies could even deliver superior results when added to the five senses. There is also a role for artificial intelligence.

3. Control room modernization: suggest collaboration with the NRC going forward.

4. Accident tolerant fuel is essential to survival of the operating fleets. This work must be a priority.

5. Digital systems common cause failure resolution. Issue with safety-related digital upgrades is a perceived need to address common multiple failures due to software. A program to define reasonable failures and testing to prevent would be helpful. 
6. Big data information sharing. I would like to see more "big data" concepts used to share information between plants. Use the ICES and other databases to mine information and connect with other data sources.

7. Secondary Benefits of I\&C Modernization. Utilities need to invest in modernization of control room I\&C systems to deal with obsolescence of the existing $30+$ year old technology and to continue operating into the future. With the new technology comes new capability that could be exploited to improve plant performance, tighten excessive margins, improve fuel utilization, etc.

8. Licensing. Current methods of digital modernization are not cost effective, due to the implementation of digital technology within the legacy analog I\&C and HSI architecture of existing plants. A cost-effective modernization that also yields ongoing operating and maintenance (O\&M) cost reduction requires significant integration of plant systems/functions to reduce the digital equipment needed. This integration may be perceived to challenge some traditional licensing guidance. In the same manner that utilities were not willing to undertake the licensing risk of new ALWR technology, they are not willing to undertake the licensing risk of modern digital integration. In a manner similar to DOE's sponsoring of early Advanced Light Water Reactor (ALWR) licensing, DOE should jump start control room modernization by facilitating the NRC review and approval of highly integrated digital systems for control room modernization.

9. HSI Phased Implementation. Current methods of digital modernization are not cost effective, due to the implementation of digital technology within the legacy analog I\&C and HSI architecture of existing plants. A cost-effective modernization that also yields ongoing O\&M cost reduction requires significant integration of plant systems/functions to reduce the digital equipment needed. This integration may be perceived to challenge some traditional licensing guidance. In the same manner that utilities were not willing to undertake the licensing risk of new ALWR technology, they are not willing to undertake the licensing risk of modern digital integration. In a manner similar to DOE's sponsoring of early ALWR licensing, DOE should jump start control room modernization by facilitating the NRC review and approval of highly integrated digital systems for control room modernization.

\section{Summary}

In all, the feedback provided by the External Review participants is taken to be a strong endorsement of the types of projects being conducted by the pathway, the value they hold for the nuclear plants, and the general timing of need. The feedback aligns well with the priorities, levels of efforts allocated for the research projects, and project schedules. This is not unexpected in that the pathway has worked with utility partners, suppliers, and industry support groups throughout the history of the program to gain a direct understanding of the needs and challenges facing the stations. Indeed, many meetings and discussions have been held with knowledgeable people in the industry, from chief nuclear officers, senior station managers, as well as the staff who conduct these related activities day-to-day.

That said, the pathway very much appreciates the insights and suggested improvements provided by the External Review participants. The feedback represents realistic observations on the practicality of some aspects of implementing these technologies. In some cases, the participants provided thoughtful challenges to certain assumptions in the formulation of the technologies or in deployment plans. These deserve further review and revision of plans if warranted.

The pathway will take all of the feedback and address the open issues that have been identified by the participants. This includes, but is not limited to, the following items: 
1. For control room modernization, further work on the business case and return on investment for a range of implementation options.

2. For control room modernization, continued support of industry efforts, particularly through NEI, to resolve regulatory issues associated with digital $\mathrm{I} \& \mathrm{C}$ implementation.

3. For computerized operator support systems, additional work to communicate the benefits of the technology to industry stakeholders.

4. For computerized operator support systems, explore potential commercialization opportunities.

5. For computer-based procedures, work with utilities, NITSL, and potential technology suppliers on a cost-effective means of converting the current paper-based procedures to computer-based procedures.

6. For computer-based procedures, continue efforts to communicate the cost-savings potential of the technology.

7. For advanced outage control centers, consider additional efforts to document the actual cost savings of the early adopters of these new technologies.

8. For wireless valve position monitoring, investigate issues of wireless infrastructure deployment and wireless cyber security issues, as potential constraints in the deployment of this technology.

9. For wireless valve position monitoring, conduct additional communications with industry stakeholders on the potential of this technology to reduce plant operating costs.

10. For general feedback on the II\&C Pathway research program, conduct additional industry engagement activities to communicate the content and value of this research program to as many industry stakeholders as possible.

11. For additional topics of potential research, evaluate these recommendations and channel them to the appropriate research programs for consideration.

In summary, the External Review has been a very valuable exercise for the II\&C Pathway, resulting in practical insights that will improve the focus of the research and enhance the value of the developing technologies to the benefit of the nuclear power industry. Again, the pathway sincerely appreciates the willingness of the NEI Digital I\&C Working Group to serve in the role of the External Review panel and for the efforts of those members of the Working Group who provided their comments, insights, and suggestions for improvement.

\section{References}

1. Hallbert, B., Thomas, K., Advanced Instrumentation, Information, and Control Systems Technologies Technical Program Plan for FY 2017, INL/EXT 1328055 Revision 6, Idaho National Laboratory, Idaho Falls, ID, 2016

2. National Research Council, Digital Instrumentation and Control Systems in Nuclear Power Plants - Safety and Reliability Issues, Washington, DC, 1997

3. Thomas, K., Lawrie, S., Niedermuller, J., A Business Case for Nuclear Plant Control Room Modernization, INL/EXT-16-39098, Idaho National Laboratory, Idaho Falls, ID, 2016

4. Thomas, K., Boring, R., Lew, R., Ulrich, T., A Computerized Operator Support System Prototype, INL/EXT-13-29751, Idaho National Laboratory, Idaho Falls, ID, 2013 
5. Vilim, R., Park, Y., Grelle, A., Parameter-Free Conservation-Based Equipment Fault Diagnosis, Argonne National Laboratory, Lemont, IL, 2016

6. Institute of Nuclear Power Operations (INPO), SOER 10-2 Engaged, Thinking Organization, Atlanta, GA, 2010

7. Thomas, K., Lawrie, S., Niedermuller, J., A Business Case for Advanced Outage Management, INL/EXT-16-38265, Idaho National Laboratory, Idaho Falls, ID, 2016

8. Naser, J., Agarwal, V., Intelligent Plant Configuration Management Using Wireless Sensors: Application to Nuclear Power Plant Valves, EPRI Report No. 3002005325, Electric Power Research Institute, Charlotte, NC, 2015 


\section{Appendix A}

\section{External Review Feedback Form}


DOE Light Water Reactor Sustainability (LWRS) Program Advanced Instrumentation, Information, and Control (II\&C) Systems Technologies Pathway

NEI Digital Working Group - Survey

August 10, 2016

Please provide feedback on the current research areas based on the needs and priorities of the current nuclear operating fleet.

Name (optional):

Organization (optional):

Organization Type:

Utility _ Industry Support Organization __ Supplier __ Other __ _ (Check One)

Control Room Modernization

Value to the Nuclear Industry: (Circle one)

5

4

High Value

Medium Value
$2 \quad 1$

Low Value

Comments:

Timeframe of Industry Need: (Circle One)

5

Now

Comments:
4

3

Next 5 Years

2

1

Next 10 Years

\section{Computerized Operator Support Systems}

Value to the Nuclear Industry: (Circle one) 
Comments:

Timeframe of Industry Need: (Circle One)

5

Now
3

Next 5 Years
2

1

Next 10 Years

Comments:

\section{Computer-Based Procedures}

Value to the Nuclear Industry: (Circle One)

$\begin{array}{lllll}5 & 4 & 3 & 2 & 1\end{array}$

High Value

Medium Value

Low Value

Comments:

Timeframe of Industry Need: (Circle One)

5

Now

4

3

Next 5 Years
2

1

Next 10 Years

Comments:

\section{Advanced Outage Control Center}

Value to the Nuclear Industry: (Circle One) 
Comments:

Timeframe of Industry Need: (Circle One)

5

Now

Comments:
4

3

Next 5 Years
2

1

Next 10 Years

\section{Wireless Remote Valve Position Monitoring}

Value to the Nuclear Industry: (Circle One)

5

4

3

Medium Value
2

1

High Value

Comments:
Low Value

Timeframe of Industry Need: (Circle One)

5

4

Now

Comments:
3

Next 5 Years
2 1

Next 10 Years

General Comments on the LWRS Program Summary and Objectives: 
Additional Technology Research Needed:

Topic:

Brief Description:

Topic:

Brief Description:

Topic:

Brief Description: 


\section{Appendix B}

\section{External Review Feedback Comments}




\begin{tabular}{|c|c|}
\hline \multirow[t]{10}{*}{$\begin{array}{l}\text { Control Room } \\
\text { Modernization - } \\
\text { Comments on Value }\end{array}$} & $\begin{array}{l}\text { Engaging operators in upfront process is very good. Think about presenting alarms, light } \\
\text { boxes, and other patterns that are recognizable by experienced operators - } \\
\text { tremendous human factors benefits. Think about synthesizing integrated plant } \\
\text { operations in future designs. }\end{array}$ \\
\hline & $\begin{array}{l}\text { Good proactive effort to get ahead of the curve with best practices for strategic } \\
\text { planning and integration of HMI for digital upgrades. }\end{array}$ \\
\hline & This is a big cost item and until regulations are changed, this will not go forward fast. \\
\hline & Need will be based on not only ease of licensing but also cost. \\
\hline & $\begin{array}{l}\text { Control Room Modernization provides a superior tool for controlling and monitoring } \\
\text { the plant. }\end{array}$ \\
\hline & $\begin{array}{l}\text { Original I\&C systems are obsolete and getting more difficult maintain. Control room } \\
\text { modernization is necessary to ensure the continued reliable operation of the existing } \\
\text { fleet, and to enable future life extensions. }\end{array}$ \\
\hline & $\begin{array}{l}\text { Control room modernization offers the potential for significant operator and I\&C } \\
\text { maintenance staff reduction. Staffing reduction is essential for the nuclear industry to } \\
\text { remain competitive in the energy production. }\end{array}$ \\
\hline & $\begin{array}{l}\text { Modernization has proven to improve safety for every industry, e.g., aviation. Nuclear } \\
\text { Industry should be in the forefront instead of lagging behind. }\end{array}$ \\
\hline & $\begin{array}{l}\text { Very good effort and value. I would choose " } 5 \text { " but cannot confirm how transportable } \\
\text { the effort is to the entire industry. }\end{array}$ \\
\hline & $\begin{array}{l}\text { Control rooms need upgrading. The analog world is shrinking and we need to upgrade } \\
\text { as an industry or face extinction. We no longer have the luxury to wait, we need to } \\
\text { improve operator performance and technology can support operators in their quest to } \\
\text { improve. }\end{array}$ \\
\hline \multirow{7}{*}{$\begin{array}{l}\text { Control Room } \\
\text { Modernization - } \\
\text { Comments on Timeframe }\end{array}$} & $\begin{array}{l}\text { Legacy plants will only modernize when dictated by economics. It will ultimately happen } \\
\text { but in varying degrees based on forecasted plant remaining life and cost of operations. }\end{array}$ \\
\hline & $\begin{array}{l}\text { Economic factors are impacting the industry, so my guess is that this will be a longer } \\
\text { time effort to implement. }\end{array}$ \\
\hline & $\begin{array}{l}\text { The modernization project will be a must in the near future once the benefits are } \\
\text { recognized by the industry. }\end{array}$ \\
\hline & $\begin{array}{l}\text { The need is urgent, and the problem will only continue to get worse if plants do not } \\
\text { upgrade aging equipment. }\end{array}$ \\
\hline & $\begin{array}{l}\text { Nuclear control room modernization should have been initiated years ago, as it was in } \\
\text { the process industries and conventional power industry. Control room modernization is } \\
\text { a long process that will require implementation over several plant cycles. Initiating } \\
\text { control room modernization now will facilitate significant staffing reductions five to } 10 \\
\text { years from now. }\end{array}$ \\
\hline & $\begin{array}{l}\text { All nuclear plants outside of the U.S. have been modernized in some way to improve } \\
\text { the public perception of nuclear safety. Doing nothing does not help improve that } \\
\text { perception in the U.S. }\end{array}$ \\
\hline & $\begin{array}{l}\text { We are late getting started. Upgrading control rooms improve plant operation and } \\
\text { supports safe operation. }\end{array}$ \\
\hline \multirow{4}{*}{$\begin{array}{l}\text { Computerized Operator } \\
\text { Support Systems - } \\
\text { Comments on Value }\end{array}$} & Interesting technology, but not sure if this is solving a significant problem for utilities. \\
\hline & $\begin{array}{l}\text { COSS facilitate operator staff reduction, because they reduce operator task burden } \\
\text { related to routine power evolutions, abnormal event diagnose and optimum response. }\end{array}$ \\
\hline & The hurdle is with the utilities willingness to modernization. \\
\hline & $\begin{array}{l}\text { I believe this will help reduce plant events by helping operators. Not sure how this will } \\
\text { be implemented at stations. }\end{array}$ \\
\hline
\end{tabular}




\begin{tabular}{|c|c|}
\hline \multirow{3}{*}{$\begin{array}{l}\text { Computerized Operator } \\
\text { Support Systems - } \\
\text { Comments on Timeframe }\end{array}$} & Considering other priorities, not sure if there is an urgent need for this technology. \\
\hline & $\begin{array}{l}\text { Especially needed as plants transition to a load following or frequency regulating } \\
\text { operating mode. }\end{array}$ \\
\hline & There are higher priorities. \\
\hline \multirow[t]{8}{*}{$\begin{array}{l}\text { Computer-Based } \\
\text { Procedures - Comments } \\
\text { on Value }\end{array}$} & $\begin{array}{l}\text { Tremendous cost-savings opportunity. Target should be to reduce manpower } \\
\text { necessary to maintain procedures and to execute in the field. Could eliminate } 2^{\text {nd }} \text { party } \\
\text { checks and verifications. }\end{array}$ \\
\hline & This is the future for the "next generation" nuclear worker. \\
\hline & $\begin{array}{l}\text { The current economic situation of the nuclear industry dictates that plants reduce O\&M } \\
\text { costs. This is an excellent initiative that can save significant costs for the utilities. This } \\
\text { would give real-time status and reduce paper. This also could reduce rad waste for } \\
\text { paper not being taken into contaminated areas. }\end{array}$ \\
\hline & $\begin{array}{l}\text { Tremendous time saving value and excellent immediate status update capabilities } \\
\text { which keep the station informed of progress in the field. Reduces paper work and } \\
\text { vulnerability of losing or misplacing work orders. }\end{array}$ \\
\hline & Interesting technology, but not sure if this is solving a significant problem for utilities. \\
\hline & $\begin{array}{l}\text { CBP can reduce human performance errors. CBP also facilitates operator staff reduction } \\
\text { due to the seamless interface with video display unit graphical displays and soft } \\
\text { controls, which allows one operator to execute most procedures. }\end{array}$ \\
\hline & $\begin{array}{l}\text { Best value when coupled with computerized operator support systems. I see most } \\
\text { value when process data is entered directly in the procedure. }\end{array}$ \\
\hline & $\begin{array}{l}\text { Efficiency is critical for the industry. The nuclear promise is requiring savings that can } \\
\text { best be realized by the use of technology. }\end{array}$ \\
\hline \multirow{5}{*}{$\begin{array}{l}\text { Computer-Based } \\
\text { Procedures - Comments } \\
\text { on Timeframe }\end{array}$} & Implementing this will be difficult to justify for small, non-fleet plants. \\
\hline & Considering other priorities, not sure if there is an urgent need for this technology. \\
\hline & $\begin{array}{l}\text { Human performance errors may be the most significant threat to plant availability and } \\
\text { safety. }\end{array}$ \\
\hline & $\begin{array}{l}\text { Procedure upgrades are very labor intensive. Study should look at "most bang for the } \\
\text { buck" or this will be very difficult to implement. }\end{array}$ \\
\hline & $\begin{array}{l}\text { I can't imagine the industry using paper procedures for the next } 20 \text { years. The sooner } \\
\text { we transfer over, the more benefit we can achieve quicker. }\end{array}$ \\
\hline \multirow{7}{*}{$\begin{array}{l}\text { Advanced Outage Control } \\
\text { Center-Comments on } \\
\text { Value }\end{array}$} & Seems to be high value based on results so far. \\
\hline & $\begin{array}{l}\text { This is an excellent initiative to allow the plants to improve communication and real- } \\
\text { time status of the outage. There should be a business case developed based on what } \\
\text { plants have experienced that have implemented this. This would help plants make a } \\
\text { decision to move forward. }\end{array}$ \\
\hline & $\begin{array}{l}\text { Has obvious potential to improve outage performance and therefore positively } \\
\text { influence capacity factor. Clearly beneficial for utilities. }\end{array}$ \\
\hline & $\begin{array}{l}\text { Outage management is essential to minimize outage duration and ensure the } \\
\text { correctness of outage activity execution. }\end{array}$ \\
\hline & Improving outage performance has obvious benefits to the nuclear industry. \\
\hline & $\begin{array}{l}\text { Most OCC's that I have seen have been upgraded significantly in the last } 10 \text { years. Not } \\
\text { sure how much more will be gained. }\end{array}$ \\
\hline & $\begin{array}{l}\text { Needed. Outages are extremely complex and need the information flow to support } \\
\text { decision making. }\end{array}$ \\
\hline $\begin{array}{l}\text { Advanced Outage Control } \\
\text { Center - Comments on } \\
\text { Timeframe }\end{array}$ & $\begin{array}{l}\text { Prioritization for individual utilities will be somewhat dependent upon the perceived } \\
\text { benefit for each utility. Each utility may be different depending on current outage } \\
\text { practices and the track record of those practices. }\end{array}$ \\
\hline
\end{tabular}




\begin{tabular}{|c|c|}
\hline & $\begin{array}{l}\text { While the industry has made significant progress in outage efficiencies, continuous } \\
\text { improvement is necessary to remain competitive in the energy industry. }\end{array}$ \\
\hline & This can be implemented without regulatory approval. \\
\hline \multirow{9}{*}{$\begin{array}{l}\text { Wireless Valve Position } \\
\text { Monitoring - Comments } \\
\text { on Value }\end{array}$} & If this could scale - quite valuable in reducing line-up verification. \\
\hline & $\begin{array}{l}\text { Not sure of value of manual valve position indication. Wireless is also a challenge to } \\
\text { implement. Other examples are also a possibility, like for protection. }\end{array}$ \\
\hline & $\begin{array}{l}\text { This will be very difficult to implement with the cyber security issues of today. Most } \\
\text { plants look at the risk and will not do it based on risk factors. }\end{array}$ \\
\hline & Great instantaneous monitoring of plant equipment, eliminates untimely discoveries. \\
\hline & Considering other priorities, not sure if there is an urgent need for this technology. \\
\hline & $\begin{array}{l}\text { While incorrect hand wheel valve position can be a significant threat to plant safety, in } \\
\text { recent years, plants have focused on configuration control using conventional manual } \\
\text { methods to greatly reduce this threat. When operations staff is reduced, including } \\
\text { reduction or elimination of Auxiliary (non-licensed) Operators, wireless remote valve } \\
\text { position monitoring would be a significant benefit to maintaining this level of plant } \\
\text { safety. }\end{array}$ \\
\hline & $\begin{array}{l}\text { This is perhaps the first step to introduce wireless into nuclear instrumentation. But a } \\
\text { business case needs to be made. }\end{array}$ \\
\hline & $\begin{array}{l}\text { I don't see a lot of important valves without position indication now. Seems like the } \\
\text { infrastructure cost for wireless might limit the overall value of this. }\end{array}$ \\
\hline & This is a great idea, but not as important as other areas. \\
\hline \multirow{2}{*}{$\begin{array}{l}\text { Wireless Valve Position } \\
\text { Monitoring - Comments } \\
\text { on Timeframe } \\
\text { (avg. rating }=2.7 \text { ) }\end{array}$} & Considering other priorities, not sure if there is an urgent need for this technology. \\
\hline & $\begin{array}{l}\text { This capability is needed concurrent with operations staff reduction; with control room } \\
\text { modernization, this is expected five to ten years from now. }\end{array}$ \\
\hline
\end{tabular}




\section{Appendix C}

External Review Value and Time Frame Ratings 


\section{External Review Feedback Form Responses}

\begin{tabular}{|c|c|c|c|c|c|c|c|c|c|c|}
\hline \multirow{2}{*}{$\begin{array}{l}\text { Organization } \\
\text { Represented }\end{array}$} & \multicolumn{2}{|c|}{$\begin{array}{l}\text { Control Room } \\
\text { Modernization }\end{array}$} & \multicolumn{2}{|c|}{$\begin{array}{c}\text { Computerized } \\
\text { Operator Support }\end{array}$} & \multicolumn{2}{|c|}{$\begin{array}{c}\text { Computer-Based } \\
\text { Procedures }\end{array}$} & \multicolumn{2}{|c|}{$\begin{array}{c}\text { Advanced Outage } \\
\text { Control Center }\end{array}$} & \multicolumn{2}{|c|}{$\begin{array}{c}\text { Wireless Valve } \\
\text { Position Monitoring }\end{array}$} \\
\hline & Value & Timeframe & Value & Timeframe & Value & Timeframe & Value & Timeframe & Value & Timeframe \\
\hline Utility & & 3 & & & 4 & 4 & 4 & 4 & 5 & 4 \\
\hline Supplier & 4 & 3 & & & 4 & 3 & 4 & 4 & 3 & 3 \\
\hline Supplier & 3 & 2 & & & 5 & 5 & 5 & 4 & 4 & 2 \\
\hline Utility & 5 & 2 & 3 & 3 & 4 & 4 & 4 & 4 & 1 & 1 \\
\hline Supplier & 4 & 1 & 3 & 3 & 3 & 3 & 4 & 4 & 3 & 2 \\
\hline Utility & 5 & 4 & 5 & 4 & 5 & 4 & 5 & 4 & 5 & 4 \\
\hline Supplier & 5 & 5 & 3 & 3 & 3 & 3 & 4 & 4 & 2 & 2 \\
\hline Supplier & 5 & 5 & 4 & 3 & 3 & 3 & 4 & 4 & 3 & 3 \\
\hline Supplier & 5 & 5 & 4 & 3 & 5 & 5 & 4 & 3 & 3 & 3 \\
\hline Industry Support & 5 & 5 & 4 & 5 & 5 & 5 & 4 & 5 & 4 & 3 \\
\hline Industry Support & 4 & 5 & 3 & 3 & 4 & 3 & 3 & 3 & 2 & 3 \\
\hline Utility & 4 & 4 & 4 & 3 & 3 & 3 & 3 & 2 & 2 & 2 \\
\hline Industry Support & 5 & 5 & 5 & 4 & 5 & 5 & 4 & 5 & 3 & 3 \\
\hline Total & 54 & 49 & 38 & 34 & 53 & 50 & 52 & 50 & 40 & 35 \\
\hline Average & 4.5 & 3.8 & 3.8 & 3.4 & 4.1 & 3.8 & 4.0 & 3.8 & 3.1 & 2.7 \\
\hline
\end{tabular}

